\title{
POLÍTICAS SOCIAIS DE INCLUSÃO SOCIAL PARA PESSOAS COM DEFICIÊNCIA
}

\author{
SOCIAL POLICIES OF SOCIAL INCLUSION FOR PEOPLE WITH DISABILITIES \\ POLÍTICAS SOCIALES DE INCLUSIÓN SOCIAL PARA PERSONAS CON DISCAPACIDAD
}

\author{
Juliana Cavalcante Marinho Paiva* \\ Pedro F. Bendassolli*
}

\begin{abstract}
RESUMO
O objetivo deste artigo é compreender como a temática da deficiência se desenvolveu no campo das políticas públicas brasileiras depois dos anos 1970 até os dias atuais. Especificamente, buscou-se identificar os principais marcos legais e políticos da inclusão social das PCD e caracterizar essa população, a fim de compreendermos mais acerca da realidade brasileira. Por meio de uma pesquisa documental, os resultados indicaram que, no Brasil, o movimento social das PCD se intensificou após o regime militar e ganhou contribuições de diferentes órgãos na hierarquia governamental brasileira, dentre os quais a CORDE e o CONADE, que, junto à Secretaria de Direitos Humanos, têm implementado e regulamentado ações de inclusão no país. Também se verificou que a população de PCD tem menos acesso à educação, salários menores e várias outras desvantagens, se comparadas à das pessoas sem deficiência, demonstrando que leis de inclusão no trabalho, dentre outras ações, ainda são muito necessárias.
\end{abstract}

Palavras-chave: Pessoas com deficiência. Políticas sociais. Trabalho.

\begin{abstract}
The objective of this study is to understand how disability issues developed in the field of Brazilian public policies after the ' 70 s to the present day. Specifically, identify the key legal and policy frameworks for social inclusion of PWD and characterize this population in order to understand more about the Brazilian reality. Through documentary research, the results indicated that in Brazil, the social movement of PWD intensified after the military regime, and earned contributions of different organs in the Brazilian hierarchy government, among which CORDE and CONADE with the help of secretariat of human rights, it has implemented and regulated inclusion initiatives in the country. It was also found that the population of PWD
\end{abstract}

\footnotetext{
* Universidade Federal do Rio Grande do Norte (UFRN), Rio Grande do Norte, Brasil. Mestre em psicologia pela mesma instituição.E-mail: jc_julianac@yahoo.com.br

** Universidade Federal do Rio Grande do Norte (UFRN), Rio Grande do Norte, Brasil. Doutor em psicologia social pela USP. Professor de psicologia do trabalho e das organizaçóes no Departamento de Psicologia, UFRN. E-mail: pbendassolli@gmail. com
} 
have less access to education, lower wages and a number of disadvantages compared to people without disabilities, demonstrating that the inclusion actions like law that guarantee access to work, among other actions are still necessary.

Keywords: People with disabilities. Social policies. Work.

\section{RESUMEN}

El objetivo de este estudio es entender cómo los temas de discapacidad son desarrollados en el campo de las políticas públicas de Brasil después de los años 70 hasta la actualidad. En concreto, hemos tratado de identificar los marcos legales y de políticas clave para la inclusión social de las personas con discapacidad, y caracterizar esta población con el fin de comprender mejor la realidad brasileña. A través de la investigación documental, los resultados indicaron que en Brasil, el movimiento social de la PCD se intensificó después del régimen militar, luego se ganaron las contribuciones de los diferentes órganos de la jerarquía de Brasil entre los que, CORDE y CONADE junto con la secretaría de derechos humanos ha implementado y regulado iniciativas de inclusión en el país. También se encontró que la población de PCD tiene menos acceso a la educación, los salarios más bajos y una serie de desventajas en comparación con las personas sin discapacidad; lo que demuestra que la inclusión de las leyes en el trabajo, entre otras acciones, siguen siendo necesarias.

Palabras clave: Las personas con discapacidad. Las políticas sociales. Trabajo.

\section{INTRODUÇÃO}

Talar sobre a temática da deficiência não é uma tarefa fácil, principalmente por se tratar de um tema que pode ser estudado por diversas vertentes: a vertente histórica, a psicológica, a do direito, a da educação, entre outras. Além disso, retraçar o histórico acerca das PCD - Pessoas com Deficiência, devido ao modo pelo qual elas foram tratadas ao longo do tempo, não é uma tarefa precisa, já que não se trata de um processo contínuo nem homogêneo, variando de um lugar para outro num mesmo período histórico (Silva, 1987). De maneira geral, os indícios históricos apontam para uma realidade de exclusão social das pessoas com deficiência, seja por elas não poderem defender o grupo social a que pertenciam, como em Esparta, seja por representarem um custo social para o Estado, como em Atenas, dentre outros exemplos de situações de exclusão social (Silva, 1987). 
Um grande marco na mudança da concepção sobre as pessoas com deficiência remonta a períodos distintos da Era Moderna. Após as Revoluçôes Industriais na Inglaterra (1760) e França (1789), começaram a aparecer registros de trabalho de pessoas com deficiência, juntamente com o aumento do trabalho feminino e infantil (Silva, 1987). Embora o motivo do aparecimento do trabalho das PCD na indústria tenha sido a necessidade de mão de obra barata, atrelado às condições de trabalho insatisfatórias para os parâmetros atuais, ressaltamos a importância desse acontecimento para a compreensão do que se configura como primeiro passo para o fenômeno da inclusão no trabalho, posto que foi um acontecimento que influenciou a percepção de que, apesar da deficiência, era possível que a pessoa exercesse algum trabalho produtivo. No início do século XIX, a criação e o aperfeiçoamento do código Braille e, no início do século XX, os registros de pelo menos 20 instituições destinadas ao atendimento de pessoas que apresentavam algum tipo de deficiência (Mazzota, 1996), também demonstram maior preocupação acerca dos cuidados com as pessoas com deficiência.

O movimento político da inclusão social começou a se evidenciar, de fato, no final do século XX, mais precisamente na segunda metade da década de 1970, nos países mais desenvolvidos, e se difundiu nas décadas de 1980 e 1990 para outros países, inclusive o Brasil (Carvalho-Freitas \& Marques 2009). O que se pode encontrar antes da década de 1970, especialmente no Brasil, são ações assistencialistas e voltadas para atividades de caridade. A Declaração dos Direitos das Pessoas Portadoras de Deficiência, aprovada pela ONU em 1975, garantiu consideraçóes específicas no planejamento econômico-social (art. 80) (Silva, 1987), contribuindo para a emergência do movimento politizado das PCD. Esse movimento visava não apenas à melhoria das condiçôes de vida das pessoas com deficiência, mas também à diminuição do estigma de "incapaz" ou "inferior", presente em alguns discursos e acontecimentos históricos anteriores, e à efetiva inclusão e participação social desse grupo na sociedade.

A inclusão, nesse sentido, refere-se à garantia de direitos e remete a uma mudança social acerca do manejo com as necessidades especiais de cada pessoa. E, dando continuidade aos acontecimentos de 1975, a ONU declarou o ano de 1981 como Ano Internacional da Pessoa Deficiente (AIPD) (Figueira, 2008), visando promover ações voltadas para esse público, bem como chamar a atenção para a questão da deficiência.

Nesse contexto de mudança de paradigma social, Sassaki (2003) pontua alguns conceitos que devem se fazer presentes na nova perspectiva sobre a inclusão das PCD, como autonomia, independência, empoderamento e equiparação de oportunidades. Segundo o autor, essas noçôes resumem a ideia de que a pessoa com deficiência deve ter o direito de exercer o controle sobre sua própria vida, 
ter domínio do espaço físico em que vive, ter condições justas de oportunidades e ter vivências que possibilitem o fortalecimento individual. Nesse sentido, a inclusão consiste em fazer com que todos os sistemas sociais estejam adequados para o máximo de possibilidades possíveis, de modo que sejam eliminadas as barreiras que impedem que todas as pessoas, com suas particularidades, possam compartilhar os mesmos ambientes e consigam ter acesso às mesmas coisas (Sassaki, 2003).

A mudança de paradigma desencadeada especialmente a partir da década de 1970 permitiu pensar nas pessoas com deficiência como participantes da sociedade e teve desdobramentos na política, nas leis, nas instituiçōes sociais como empresas e escolas, nas PCD e na sociedade de maneira geral. Os principais questionamentos que surgem em decorrência desse contexto são: quais as principais mudanças políticas no cenário brasileiro ocorridas em consequências dessa mudança de paradigma? Quais os principais marcos atuais da inclusão social das PCD no Brasil? Qual a situação atual das pessoas com deficiência no Brasil: quantas são, onde estão etc.? E que perspectivas existem para se pensar a situação das pessoas com deficiência no Brasil? $\mathrm{Na}$ tentativa de responder a tais questionamentos, este artigo tem como objetivo compreender como a temática da deficiência se desenvolveu no campo das políticas públicas brasileiras depois dos anos 1970 até os dias atuais. Especificamente, busca-se identificar os principais marcos legais e políticos da inclusão social das PCD e caracterizar essa população, a fim de compreendermos mais acerca da realidade brasileira.

\section{MÉTODO}

Para cumprir os objetivos deste estudo, foi realizado um levantamento de documentos e bibliografias (Creswell, 2007), com vistas a buscar o referencial adequado para responder aos questionamentos suscitados. Essa busca foi realizada primeiramente utilizando-se descritores como "deficiência", "pessoas com deficiência", "inclusão social", "políticas de inclusão social" e "trabalho". Como forma de complementação, após a pesquisa inicial, foi realizada uma busca em sites dos ministérios e das secretarias do governo federal.

Para análise do material, o mesmo foi organizado e dividido de acordo com o conteúdo e com questôes do estudo (Creswell, 2007). O material foi fichado e separado segundo os seguintes temas: movimento político de inclusão das PCD, trabalho e deficiência e caracterização populacional. Após a separação do material (artigos ou documentos) de acordo com os temas, desenvolveu-se uma organização lógica e, quando possível, temporal do mesmo, para que se procedesse à escrita dos achados. Dessa maneira, é possível afirmar que se trata de um estudo exploratório, de caráter documental e qualitativo. 


\section{RESULTADOS E DISCUSSÃO}

Para compreendermos as principais mudanças políticas ocorridas em função dos movimentos de inclusão, iniciados nos anos 1970, é necessário ter em vista que o governo tem ferramentas fundamentais para proporcionar a efetividade de alguma mudança social, mas precisa estar alinhado à sociedade civil e aos interesses econômicos (Brasil, 2014). E as proposições governamentais brasileiras para a diminuição da exclusão social passaram pela criação de coordenadorias, secretarias, conselhos administrativos, programas de governo, aprovação de leis e emendas constitucionais, dentre outras ações. A próxima seção discorre sobre esse tópico.

\subsection{Os marcos legais}

A Declaração dos Direitos das Pessoas Portadoras de Deficiência, aprovada pela ONU, causou um clima de debate acerca dos movimentos por garantias de direitos para essa população e, pautado no debate sobre direitos humanos em âmbito internacional, havia no Brasil um crescente debate sobre direitos iguais e inalienáveis como fundamento de justiça social (Brasil, 2010). Nesse sentido, não apenas as pessoas com deficiência começaram a ser escutadas, mas também outras minorias e grupos sociais.

A primeira representação política no Brasil das pessoas com deficiência se deu por meio da Coalisão Pró-Federação Nacional de Entidades de Pessoas Deficientes, em 1979, e contava com representantes de diversos tipos de deficiência e doenças causadoras de deficiência. No entanto, a multiplicidade de reivindicações para cada deficiência não se mostrou efetiva para manter o grupo coeso, de modo que, para o amadurecimento do debate, o grupo optou por um arranjo político que privilegiasse a criação de federaçôes representantes de cada tipo de deficiência. Esse arranjo permitiu um melhor debate acerca das questóes básicas e conceituais que ainda eram pouco desenvolvidas à época (Brasil, 2010).

Não se pode deixar de assinalar que, na época em que foi aprovada a Declaração dos Direitos das Pessoas Portadoras de Deficiência, o Brasil vivia o período do regime militar, e muitas questóes sociais eram silenciadas em prol da unicidade do governo. No início dos anos 1980, o regime militar estava enfraquecido, e, em seus momentos finais, as referências dos movimentos sociais se tornaram decisivas na Assembleia Nacional Constituinte, de modo a garantir os direitos ou representações dos movimentos sociais na Constituição de 1988. Até aquele momento, não havia registros de garantias aos direitos das pessoas com deficiência em outra Constituição (Brasil, 2010). 
Uma das representaçôes políticas de garantias de direitos das PCD mais consolidadas à época da pré-aprovação da Constituição de 1988 foi a Coordenadoria Nacional para Integração da Pessoa Portadora de Deficiência (CORDE), criada em 1986 e que, dentre outras atribuições, destinava-se a prover ações inclusivas em âmbito nacional para as PCD (Brasil, 2016). A criação da coordenadoria e a implementação da Política Nacional para Integração da Pessoa Portadora de Deficiência, em 1989, foram fundamentais para garantir o atendimento dos interesses desse grupo populacional. A CORDE passou por transformaçóes, sendo realocada para a Secretaria dos Direitos da Cidadania do Ministério da Justiça, de acordo com a Medida Provisória no 891. Ficou vinculada à Secretaria Nacional dos Direitos Humanos, que integrava o Ministério da Justiça, em 1997, e à Secretaria de Estado de Direitos Humanos, em 1999. Esta foi vinculada à Secretaria Especial dos Direitos Humanos da Presidência da República (SEDH/PR, 2003) e, finalmente, em 2009, foi transformada em Subsecretaria Nacional de Promoção dos Direitos da Pessoa com Deficiência (Brasil, 2010), o que significa uma elevação na hierarquia do governo, com mais respaldo para suas ações.

Como instrumentos de promoção dos direitos das PCD, além da CORDE, foi criado o Conselho Nacional dos Direitos da Pessoa com Deficiência (CONADE), órgão de deliberação coletiva cuja atribuição era garantir a implementação da Política Nacional de Integração da Pessoa Portadora de Deficiência. Os conselhos deliberativos têm a função de propor diretrizes, tomar decisões relacionadas às políticas e cuidar da gestão de programas, enquanto o CONADE está subordinado à Secretaria de Direitos Humanos da Presidência da República (Brasil, 2010).

Os movimentos de inclusão social são diversos e, além de secretarias, coordenadorias e conselhos, há um grande número de organizações, federações e associações. Note-se que leis diversas, benefícios e novos temas são incorporados à luta dos direitos das PCD, tendo como um dos principais ganhos a incorporação da temática aos direitos humanos, a fim de evidenciar ainda mais a garantia de direitos, com menos foco na assistência social. Uma das principais lutas dos ativistas da área buscou a aquisição da autonomia e diminuição da tutela (Brasil, 2010), apesar de algumas questôes de tutela ou de assistencialismo ainda se fazerem presentes na atuação política. Filiado ao Ministério do Desenvolvimento Social e Combate à Fome, existe o Centro de Referência de Assistência Social, por meio do qual se conseguem benefícios como o Benefício de Prestação Continuada - BPC, que consiste na concessão de um auxílio financeiro, no valor de um salário mínimo, para pessoas com deficiência ou idosos cuja renda familiar (considerando todos os membros da família) seja menor que um quarto 
do salário mínimo. Depois de adquirido, esse benefício é contínuo, mas não se equipara à aposentadoria, pois não há recebimento de férias e outros provimentos adquiridos pelo trabalho.

A Convenção sobre os Direitos da Pessoa com Deficiência, da ONU, aprovada em julho de 2008 pelo Decreto Legislativo $n^{\circ} 186$ e promulgada pelo Decreto $n^{\circ}$ 6.949, de 25 de agosto de 2009, com equivalência de emenda constitucional, foi outro marco relevante para o movimento das pessoas com deficiência. $O$ contexto legal e político associado a essas diversas proposições foram acompanhados de mudanças no modo como as pessoas envolvidas começaram a ser representadas nos discursos oficiais, como se discorre a seguir.

\subsection{Mudanças discursivas}

Devido ao processo de politização e à mudança de paradigma de exclusão para inclusão social, também começaram a mudar os nomes que designavam as pessoas com deficiência, e termos como "aleijado", "defeituoso", "incapacitado", "inválido" foram paulatinamente substituídos pela expressão "pessoa deficiente". Um avanço dado à utilização do termo "pessoa" para lembrar que, antes de ter uma deficiência, tratava-se de uma pessoa. Aos poucos, entrou em uso a expressão "pessoa portadora de deficiência", visto que não se tratava de uma pessoa deficiente, e sim de uma condição de deficiência. Essa expressão foi posteriormente reduzida para "portador de deficiência" e, mesmo que a adoção do termo "portador" demonstrasse a tentativa de diminuir o estigma, quase sempre presente quando o tema da deficiência era abordado, essa determinação não foi totalmente acolhida pelos estudiosos do assunto (Araújo, 2001). Apesar de o termo ter sido difundido, inclusive em documentos oficiais, a tendência foi cair em progressivo desuso, já que não se trata de uma condição "portada", e sim de uma característica da pessoa. Desse modo, na década de 1990, entrou em uso a expressão "pessoa com deficiência", que permaneceu até os dias atuais, sendo considerada a nomenclatura menos estigmatizante (Sassaki, 2003).

Em termos conceituais, pessoas com deficiência são aquelas que apresentam significativas diferenças físicas, sensoriais ou intelectuais, decorrentes de fatores congênitos ou adquiridos, de caráter permanente, e que acarretam dificuldades ou incapacidades em sua interação com o meio físico e social (Sassaki, 2003 \& Brasil, 2010).

O Decreto no 5.296, 2 de dezembro 2004 estabeleceu critérios técnicos fundados em parâmetros internacionais, considerando os seguintes tipos de deficiência: deficiência física, deficiência auditiva, deficiência visual, deficiência intelectual e deficiência múltipla (Brasil, 2010). Cada um desses tipos envolve 
uma quantidade insuficiente de estímulos captados pelo órgão sensorial para que se caracterize uma diferença significativa (frequência captada [em hertz], acuidade visual, dificuldades de locomoção e diagnósticos intelectuais). O Instituto Brasileiro de Geografia e Estatística (IBGE, 2010) realizou o último censo brasileiro e fez uma cartilha com os principais resultados da caracterização da população com deficiência, de acordo com a tipologia das deficiências (visual, auditiva, física/motora, intelectual) e o grau (leve e severo). Dentre tais resultados, verificou-se que $24 \%$ da população residente no país possuíam pelo menos uma das deficiências investigadas, quase $14 \%$ a mais que a média mundial, de $10 \%$.

As pessoas mais velhas são mais acometidas por alguma condição permanente que culmina numa deficiência. E também a severidade das deficiências é maior nas pessoas acima de 64 anos (Instituto Brasileiro de Geografia e Estatística [IBGE], 2010). Não à toa, a temática da deficiência se torna ainda mais importante, visto que há uma tendência, com o aumento da idade, para que se desenvolvam mais problemas de saúde que possam causar deficiência, de modo que na faixa populacional acima de 67 anos a incidência das deficiências aumenta.

E o Brasil apresenta um número cada vez maior de pessoas com deficiências adquiridas, especialmente nos Estados do Nordeste (IBGE, 2010). Isso é explicado em parte pelo grande número de acidentados no trabalho, no trânsito, pelo aumento da violência, pela falta de infraestrutura de saúde e de prevenção em saúde (Satow \&e Heloani, 2003).

As taxas de escolarização e alfabetização de PCD, comparativamente à população sem deficiência, foram menores. Em toda a rede de ensino, da educação básica à superior, as PCD têm menores índices de acesso. Nas demais comparações entre a população com deficiência e a população sem deficiência, o primeiro grupo apresenta mais desvantagens. Por exemplo, em relação à ocupação, no grupo das pessoas com deficiência, aproximadamente 23,6\% são trabalhadores, enquanto no grupo das pessoas sem deficiência $76,4 \%$ são trabalhadores (IBGE, 2010).

Apesar de os avanços médicos, as políticas públicas e os avanços tecnológicos terem possibilitado à pessoa com deficiência melhorias em suas condições de vida, é importante não perder de vista que a ideia de inclusão está imersa na realidade de exclusão (Sawaia, 2009). Segundo Satow e Heloani (2003), um dos modos de sair do estigma (inclusão pela exclusão) é a crença nas potencialidades das pessoas com deficiência, e a melhor forma de exercer essa crença é por meio do trabalho. Esse se configura como principal balizador dos processos de inclusão e de possibilidade de caracterização das pessoas com deficiência como ativas na sociedade. 


\subsection{Deficiência e trabalho}

Um dos principais e mais recente referenciais da inclusão das pessoas com deficiência é a inserção no mercado de trabalho formal (Carvalho-Freitas \& Marques 2009). E, ainda, segundo Carvalho-Freitas e Marques, a inclusão começou efetivamente quando a Constituição Federal garantiu os direitos de acesso à educação, ao trabalho, às formas de interação social, como o esporte $\mathrm{e}$ o lazer, entre outros, às pessoas com deficiência. E, com a homologação da Lei no 8.213, art. 93 (1993), o acesso ao trabalho ganhou consideraçôes específicas. A lei determina que toda empresa com 100 ou mais empregados está obrigada a preencher de $2 \%$ a $5 \%$ dos seus cargos com beneficiários reabilitados ou pessoas portadoras de deficiência. Essa lei contribuiu para uma crescente preocupação com a empregabilidade formal de pessoas com deficiência e sua inserção no mercado de trabalho. Como consequência, instituições sociais, como as de educação, foram incumbidas da missão de preparar tais pessoas para o mercado de trabalho, até então escasso (Toldrá \& Sá, 2008), transformando a via de acesso ao trabalho para as pessoas com deficiência e transformando também o acesso à educação, de modo a possibilitar uma mudança na situação social dessas pessoas e viabilizar sua inclusão nos meios sociais.

Passados mais de 20 anos desde que a lei entrou em vigor, ainda há impedimentos para que a inserção seja plenamente efetuada, pois ainda se verifica a má qualificação profissional de quem não teve acesso a uma educação adequada e, em oposição, o desconhecimento da capacidade de trabalho das PCD, por parte dos gestores (Carvalho-Freitas, 2009, 2010). Contudo, muitas evoluções são visíveis, como a pressão governamental para a garantia do cumprimento da lei, o investimento em capacitação profissional, por parte das empresas, e a autonomia proporcionada a um grande número de PCD, que podem, então, ter seu direito ao trabalho garantido.

\section{CONSIDERAÇÕES FINAIS}

Como dito no início deste artigo, há que se considerarem vários fatores históricos, jurídicos, psicológicos, bem como tantos outros, para se compreender o fenômeno da inclusão/exclusão vivenciado pelas pessoas com deficiência.

Em resposta ao objetivo da pesquisa, que visava compreender como a temática da deficiência se desenvolveu no campo das políticas públicas brasileiras, depois dos anos 1970 até os dias atuais, foram especificados temporalmente os principais marcos acerca dos movimentos políticos no Brasil: a aprovação da Declaração dos Direitos das Pessoas Portadoras de Deficiência; as implicações no contexto vivenciado pelo Brasil do regime militar; a formação da Coalisão 
Pró-Federação Nacional de Entidades de Pessoas Deficientes; o surgimento da CORDE e do CONADE e a entrada da temática na Secretaria de Direitos Humanos.

Particularmente, buscou-se identificar os principais marcos legais, explicitados pelo BPC e pela Lei 8.213/91, que trazem consideraçóes específicas de acesso ao trabalho para as PCD, garantindo assim formas de inclusão social mais amplas e completas, pois o trabalho permite, dentre outras coisas, interação e participação social. Por fim, o objetivo de compreender mais a realidade brasileira foi atendido com os dados fornecidos pelo IBGE acerca da temática, o que evidenciou ainda as desigualdades comparativas entre as populaçōes com e sem deficiência, tendo a última mais acesso em todos os quesitos, como trabalho, educação e salário. Também se evidenciou que a pobreza e a violência são fatores que favorecem o acometimento de deficiências adquiridas. Isso deixa claro que a abordagem do tema não deve ser isolada, no discurso de garantias de direitos para as pessoas com deficiência, pois ele compreende não só garantia à saúde, à educação e ao trabalho em condiçôes dignas, mas ainda garantia à vida ou a todos os requisitos de respeito à vida. Essa tarefa compete, pois, não só aos governos, mas a todos os atores sociais engajados na luta pelos direitos dos cidadãos, sejam eles marcados ou não pelo estigma da deficiência. 


\section{REFERÊNCIAS}

Araújo, L. A. D. (2001). A proteção constitucional das pessoas portadoras de Deficiência. Brasília, Coordenadoria Nacional para Integração da Pessoa Portadora de Deficiência.

Brasil (2010). História do Movimento Político das Pessoas com Deficiência no Brasil. Brasília: Secretaria de Direitos Humanos. Recuperado a partir de http://www.portalinclusivo.ce.gov.br/phocadownload/publicacoesdeficiente/ historia\%20movimento\%20politico\%20pcd\%20brasil.pdf

Brasil (2014). Ministério do Desenvolvimento Social. Recuperado a partir de http://mds.gov.br/

Brasil (2016). Ministério dos Direitos Humanos. Secretaria Nacional de Promoção dos Direitos da Pessoa com Deficiência. Recuperado a partir de http://www.pessoacomdeficiencia.gov.br/app/

Carvalho-Freitas, M. N. de \& Marques, A. L. (2009). Pessoas com deficiência e trabalho: percepção de gerentes e pós-graduandos em Administração. Psicologia: Ciência e Profissão, 29(2), 244-257.

Carvalho-Freitas, M. N. de, Toledo, I. D., Nepomuceno, M. F., Suzano, J. de C. C., \& Almeida, L. A. D. (2010). Socialização organizacional de pessoas com deficiência. Revista de Administração de Empresas, 50(3), 264-275.

Creswell, J. W. (2007). Projeto de pesquisa: métodos qualitativo, quantitativo e misto. (2a ed.) Porto Alegre: Artmed.

Decreto no 5.296 (2004, 2 de dezembro). Regulamenta as Leis nos 10.048, de 8 de novembro de 2000, que dá prioridade de atendimento às pessoas que especifica, e 10.098, de 19 de dezembro de 2000, que estabelece normas gerais e critérios básicos para a promoção da acessibilidade das pessoas portadoras de deficiência ou com mobilidade reduzida, e dá outras providências. Diário Oficial da União, Brasília-DF. Recuperado a partir de http://www.planalto. gov.br/ccivil_03/_ato2004-2006/2004/decreto/d5296.htm

Decreto no 6.949 (2009, 25 de agosto). Promulga a Convenção Internacional sobre os Direitos das Pessoas com Deficiência e seu Protocolo Facultativo, assinados em Nova York, em 30 de março de 2007. Diário Oficial da União, Brasília-DF. Recuperado a partir de http://www.planalto.gov.br/ccivil_03/_ ato2007-2010/2009/decreto/d6949.htm

Figueira, E. (2008). Caminhando em silêncio: uma introdução à trajetória das 
pessoas com deficiência na história do Brasil. Giz Editorial, São Paulo.

Instituto Brasileiro de Geografia e Estatística (2010). Censo demográfico: resultados preliminares. Brasil.

Lei no 8.213 de 24 de julho de 1991. (1998, 14 agosto). Dispõe sobre os Planos de Benefícios da Previdência Social e dá outras providências. Diário Oficial da União, Brasília. Recuperado a partir de http://www.planalto.gov.br/ccivil_03/ leis/L8213cons.htm

Mazzotta, M. J. S. (1996). Educação especial no Brasil-História e políticas públicas. São Paulo: Cortez.

Sassaki, R. K. (2003). Como chamar as pessoas que têm deficiência. São Paulo: RNR.

Satow, S. e Heloani, J. R. (2003). Algumas considerações sobre os portadores de deficiência. Educação on line, 1, 1-11.

Sawaia, B. (2009). Psicologia social e desigualdade: um estudo sobre liberdade e afetividade. Psicologia Social \& Sociedade, 21(3), 364-372.

Silva, O. M. (1987). A epopeia ignorada: a pessoa deficiente na história do mundo de ontem e de hoje. São Paulo: CEDAS. 1987.

Toldrá, R. C., \& Sá, M. J. C. N. A profissionalização de pessoas com deficiência em Campinas: fragilidades e perspectivas. Revista de Terapia Ocupacional da Universidade de São Paulo, 19(1), 48-55. 